\title{
Visualisasi Letak Geografis Provinsi Di Indonesia Berbasis Augmented Reality Untuk Siswa SD (Studi Kasus: SD Negeri 99 Pongrakka)
}

\author{
Suharsono Bantun*, Jayanti Yusmah Sari**, Qammaddin***, Rahmat Karim ${ }^{* * * *}$ \\ *,******** Sistem Informasi, Universitas Sembilanbelas November Kolaka \\ ** Ilmu Komputer, Universitas Sembilanbelas November Kolaka \\ E-mail: *suharsonob@usn.ac.id, ${ }^{* *}$ jayanti@ usn.ac.id, ${ }^{* * *}$ didinusn@gmail.com, ${ }^{* * * * *}$ rahmatkarim@usn.ac.id
}

\begin{abstract}
The learning implementation in the subject of social science, especially the topic of Indonesia's geographical location at SD Negeri 99 Pongrakka is still carried out in a classical way, namely using the lecture method with learning media in the form of depictions on the blackboard or just observing pictures through textbooks. These methods make the learning process less interesting and seem passive because there is no direct interaction between the topic and the students. To create interactive learning, we propose the development of learning media by utilizing Augmented Reality technology. The system proposed in this study can display the geographical location of the province in 3 dimensions by means of the user pointing the marker at the camera then the camera detects the marker and the object will be displayed directly on the monitor screen according to the marker used. After testing the system based on the Software Requirement Specification, it was able to be concluded that the application of visualizing the geographical location of the province based on Augmented Reality could not only make learning more interactive but also more interesting, so that it could be used as an option for learning methods.
\end{abstract}

Keyword: Augmented Reality, Software Requirement Specification, Social science, marker.

\section{Introduction}

Sekolah Dasar (SD) Negeri 99 Pongrakka merupakan salah satu sekolah dasar yang berada di Dusun Tabah, Kecamatan Walenrang Timur, Kabupaten Luwu. Metode yang digunakan dalam proses belajar mengajar di SD Negeri 99 Pongrakka ini yaitu metode ceramah, dimana seorang guru menerangkan dan para siswa mendengarkan penjelasan dari guru. Letak geografis provinsi di Indonesia adalah posisi provinsi-provinsi di Indonesia yang merupakan salah satu sub materi ilmu pengetahuan sosial yang wajib dipelajari oleh para siswa kelas VI. Ilmu pengetahuan sosial merupakan mata pelajaran yang terkesan membosankan dan kurang disukai bagi para siswa, apalagi dengan menggunakan metode ceramah, menggambarkan di papan tulis, atau hanya sekedar melihatnya di buku pelajaran. Metode-metode tersebut masih terkesan pasif dan statis karena tidak adanya interaksi langsung antara materi dengan para siswa, hal ini mengakibatkan mata pelajaran ini menjadi kurang menarik. Selain itu, pembahasan yang biasa ditampilkan di dalam buku menggunakan teks dan gambar kurang menarik dikarenakan terlalu banyaknya teks penjelasan dan kurangnya gambar [1]. Begitu juga dengan media website yang diharuskan terhubung ke jaringan internet, dengan tampilan interface yang tidak menarik minat masyarakat baik itu dari kalangan remaja maupun orang dewasa [1].

Untuk memenuhi tuntutan tersebut, teknologi dapat dimanfaatkan dalam upaya membantu proses pembelajaran menjadi lebih menarik. Salah satunya yang sedang marak belakang ini adalah dengan memanfaatkan teknologi Augmented Reality (AR). Teknologi AR memungkinkan pengguna untuk melihat dunia nyata bersamaan dengan objek virtual [2]. AR berbeda dengan Virtual Reality (VR) ataupun Mixed Reality (MR). AR dan MR memungkinkan pengguna dapat melihat dan berinteraksi dengan objek virtual 3 Dimensi (3D) pada lingkungan yang nyata, sedangkan VR membawa pengguna pada dunia virtual tanpa melihat ataupun berinteraksi dengan dunia nyata [2]. Menurut Mustika dkk, AR merupakan suatu konsep perpaduan antara VR dengan dunia nyata, sehingga objek-objek virtual 2 Dimensi atau 3 Dimensi seolah-olah terlihat seperti nyata dan menyatu dengan dunia nyata [3]. Untuk itu, pada teknologi AR, pengguna dapat melihat dunia nyata yang ada di sekelilingnya dengan penambahan objek virtual yang dihasilkan oleh komputer.

Dalam penelitian ini, dibuat sebuah cara baru dalam mempelajari posisi provinsi-provinsi di Indonesia yang merupakan salah satu sub materi ilmu pengetahuan sosial (IPS). Salah satu cara untuk menampilkannya adalah dengan teknologi AR. Ada beberapa penelitian yang membuktikan bahwa penggunaan teknologi AR 
dapat mempermudah guru dalam menerangkan pelajaran, menarik minat belajar dari siswa dan memperluas wawasan masyarakat umum. Penelitian terbaru menemukan bahwa penambahan objek 3D terhadap dunia nyata dapat memberikan pengalaman yang signifikan bagi pengguna [1][4][5][6][7].

Berdasarkan latar belakang masalah yang telah diuraikan di atas, maka yang menjadi pokok permasalahan adalah bagaimana menyajikan suatu model pembelajaran untuk siswa sekolah dasar yang lebih menarik khususnya mengenai letak geografis provinsi di Indonesia pada mata pelajaran Ilmu Pengetahuan Sosial. Tujuan dari penelitian ini membuat visualisasi 3D letak geografis provinsi-provinsi di Indonesia berbasis AR untuk mata pelajaran Ilmu Pengetahuan Sosial pada Sekolah Dasar. Sampel dalam penelitian ini yaitu provinsiprovinsi yang ada di Pulau Sulawesi.

\section{Research Method}

\subsection{Analisis Sistem}

Analisis sistem adalah suatu sistem yang diuraikan secara utuh ke dalam bagian-bagian komponennya dengan maksud untuk mengidentifikasi dan mengevaluasi permasalahan yang terjadi dan kebutuhan untuk perbaikan berikutnya. Hasil akhir dari analisis sistem ini adalah solusi suatu dalam bentuk spesifikasi sistem yang baru.

Sistem yang sedang berjalan saat ini dalam pembelajaran letak geografis provinsi masih terkesan pasif dan statis dengan menggunakan metode belajar konvensional yaitu guru melakukan ceramah di depan kelas, menggambarkan objek di papan tulis, sedangkan para siswa melihatnya dari buku pelajaran. Hal ini membuat pembelajaran ini menjadi kurang menarik bagi para siswa. Dengan melihat kondisi sistem saat ini, maka pada penelitian ini dirancang suatu visualisasi letak geografis 3D berbasis augmented reality (AR) yang diharapkan nantinya dapat membuat pembelajaran letak geografis provinsi menjadi lebih menarik bagi para siswa.

\subsection{Augmented Reality (AR)}

Teknologi AR ini dapat menyisipkan suatu informasi tertentu ke dalam dunia maya dan menampilkannya di dunia nyata dengan bantuan perlengkapan seperti webcam, komputer, smartphone, maupun kacamata khusus. Penggunaan teknologi ini akan sangat membantu dalam menyampaikan suatu informasi kepada pengguna. AR tidak hanya digunakan di bidang informasi dan pemasaran saja, melainkan juga digunakan di bidang Pendidikan, kesehatan, keamanan publik, dan pariwisata.

Metode yang dikembangkan pada AR saat ini terbagi menjadi dua metode, yaitu dengan marker statis dan marker dinamis [8]. Pada penelitian ini, digunakan metode pertama, yaitu marker yang bersifat statis. Dengan demikian, AR pada penelitian ini bekerja dengan menggunakan satu marker untuk satu objek dengan tahapan seperti yang ditunjukkan pada Gambar 1. Pada saat webcam aktif, maka webcam akan mengindentifikasi gambar bertanda khusus (marker) yang sering kali berupa gambar barcode hitam-putih. Software kemudian menganalisis marker tersebut dengan melakukan tracking objek dan membuat gambar virtual di layar monitor yang terhubung dengan posisi webcam. Sehingga, aplikasi tersebut bekerja dengan kamera terhadap marker untuk menyajikan tampilan 3D.

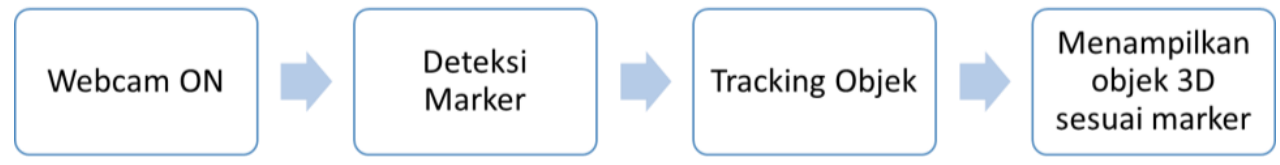

Gambar 1 Tahapan Umum Metode AR dengan Marker Based Tracking

Adapun proses pengenalan pola pada feature gambar ketika dilakukan tracking objek pada marker yaitu sebagai berikut [9].

1. Mengambil gambar dari kamera (pemerolehan data), sistem mengolah dan menganalisis frame per frame video yang di-streaming secara real time dan hasilnya berupa citra digital yang akan digunakan untuk tahap berikutnya.

2. Mengenali dan mendeteksi pola pada feature gambar dengan proses pengolahan citra digital

3. Penyesuaian Pola (pengenalan data/klasifikasi), pola marker yang telah terdeteksi berupa titik-titik keypoint akan disesuaikan dengan pola yang ada pada sistem dengan cara menyesuaikan feature dan penempatan titik keypoint pada pola gambar.

\subsection{Spesifikasi Kebutuhan}

Berikut beberapa kebutuhan pada kondisi awal untuk membuat sistem pada penelitian ini: 


\section{a. Kebutuhan Fungsional}

Adapun yang menjadi kebutuhan fungsional yaitu: 1) menampilkan objek letak geografis provinsi 3D beserta penjelasannya sesuai dengan marker yang digunakan, 2) pengguna dapat berinteraksi secara realtime, interaksi yang bisa dilakukan yaitu dengan memutar marker sehingga objek yang ditampilkan juga ikut berputar mengikuti arah putaran marker. Dengan demikian objek dapat dilihat dari berbagai sisi, dan 3) menampilkan objek letak geografis provinsi 3D berdasarkan jarak kamera dengan marker yang digunakan.

\section{b. Kebutuhan Data}

Yang menjadi kebutuhan data meliputi: 1) proses pemasukan data di mana pengguna mengarahkan marker ke kamera secara langsung, 2) proses pemrosesan marker yang diubah menjadi biner hitam putih. Setelah itu ARToolkit mencari gambar berkotak hitam dan mencocokkan dengan memory template yang ada di ARToolkit, dan 3) proses menampilkan objek 3D, meliputi ketika koordinat kamera virtual dan kamera nyata telah sama, maka grafik komputer akan menggambar dan melakukan overlay objek 3D.

\section{c. Kebutuhan Non Fungsional}

Dan yang menjadi kebutuhan non fungsional yaitu marker atau penanda yang telah didesain, kamera internal dan kamera eksternal.

\subsection{Alat dan Bahan Penelitian}

Dalam penelitian ini dibutuhkan hardware berupa komputer dengan spesifikasi processor Core i3 dengan RAM 2GB dan eksternal kamera 16MP, serta software berupa ARTToolkit, Corel Draw 2019, 3DSMax, Visual $\mathrm{C}++2008$ Express Edition, Visual Basic 6.0. Adapun bahan yang digunakan dalam penelitian ini adalah marker dan material (tekstur) letak geografis provinsi di Indonesia.

\subsection{Rancangan Arsitektur Aplikasi}

Gambar 2 merupakan rancangan arsitektur aplikasi pada penelitian ini yang meliputi capture marker, identifikasi marker, dan menampilkan objek 3 Dimensi. Untuk menampilkan objek 3D dari letak geografis provinsi di Indonesia pada layar monitor, pengguna harus mengarahkan marker ke webcam sehingga sistem akan mendeteksi marker dan menampilkan objek 3D dari letak geografis provinsi di Indonesia pada layar monitor sesuai dengan marker yang digunakan.

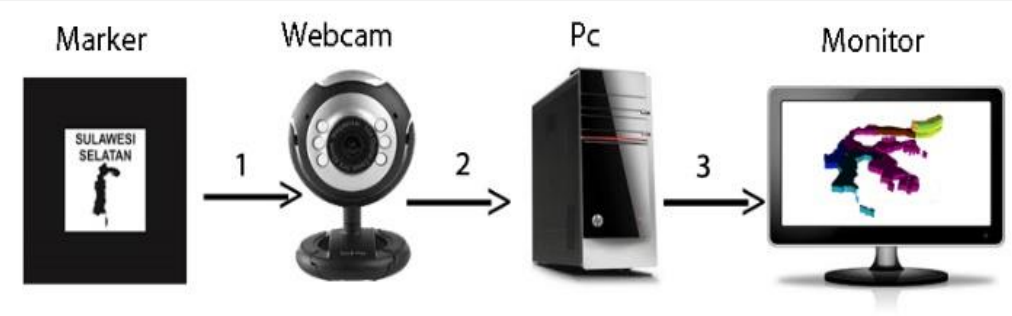

Gambar 2 Arsitektur Aplikasi

\section{Result and Analysis}

\subsection{User Interface Aplikasi}

User interface pada aplikasi ini dibuat dengan menggunakan Visual Basic 6.0 yang terdiri dari form utama, form tampilkan objek, form lihat marker, dan form tentang penulis. Pada form utama, terdapat 4 tombol yang berfungsi untuk menampilkan fungsinya masing-masing. Pengguna dapat memilih menu "tampilkan objek", "lihat marker", "tentang kami” dan "keluar". Menu "tampilkan objek" digunakan untuk menampilkan letak geografis provinsi 3D yang telah dibuat (Gambar 3b) dengan menggunakan marker (Gambar 3a).

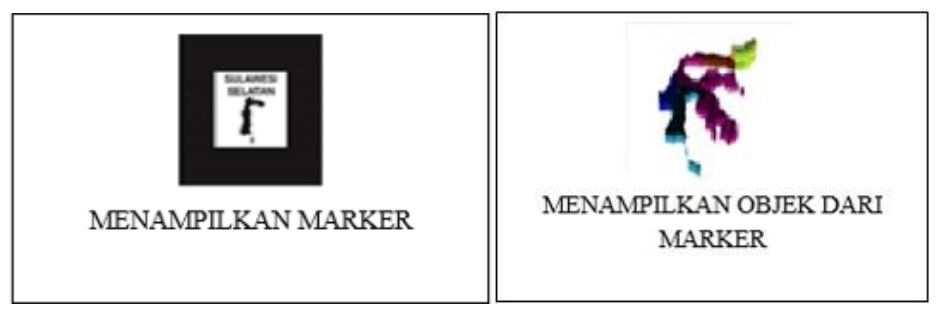

Gambar 3 a. contoh marker (kiri) dan b. gambar 3D letak geografis provinsi (kanan) 


\subsection{Hasil Pengujian}

Teknik pengujian yang dilakukan terdiri dari beberapa langkah, sesuai dengan kriteria yang menjadi tolak ukur keberhasilan sistem yang dibangun. Pengujian sistem ini didasarkan pada Software Requirement Specification (SRS) yaitu: pengujian dengan menampilkan objek letak geografis provinsi, pengujian agar pengguna dapat berinteraksi secara real time, pengujian jarak kamera dengan penanda atau marker, dan pengujian menggunakan kamera internal serta kamera eksternal.

\section{a. Pengujian dengan Menampilkan Objek Letak Geografis Provinsi}

Pada pengujian ini, dilakukan pengujian untuk menampilkan objek letak geografis provinsi beserta keterangannya sesuai dengan marker yang digunakan. Berikut adalah tampilan hasil pengujian untuk menampilkan objek sesuai dengan marker yang telah ditentukan:

Tabel 1 Pengujian Tampilan Objek

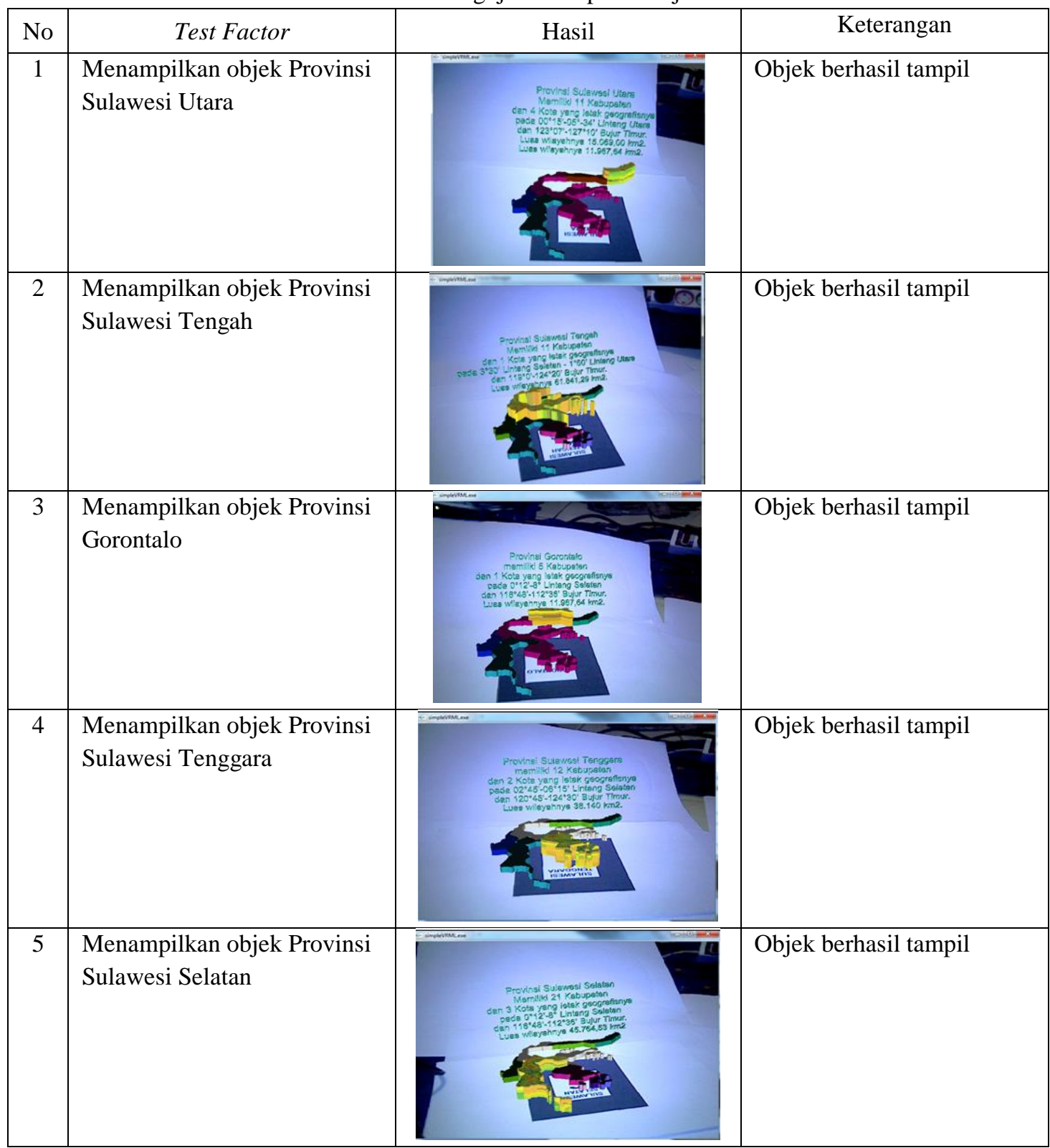

Dari hasil pengujian pada Tabel 1, dapat dilihat bahwa objek yang menjadi test factor seperti Provinsi Sulawesi Utara, Sulawesi Tengah, Gorontalo, Sulawesi Tenggara, dan Provinsi Sulawesi Selatan beserta penjelasannya berhasil tampil sesuai dengan marker yang digunakan. Dengan demikian untuk pengujian menampilkan objek-objek letak geografis provinsi ini dinyatakan berhasil. 


\section{b. Pengujian Agar Pengguna Dapat Berinteraksi Secara Real time}

Pada pengujian kedua, dilakukan pengujian terhadap dua sampel objek yaitu Provinsi Sulawesi Selatan dan Provinsi Sulawesi Tengah dengan memutar objek sehingga pengguna dapat melihatnya dari sisi depan, samping dan atas. Hasil pengujian pada Tabel 2 menunjukkan bahwa objek-objek yang ditampilkan dapat berputar mengikuti putaran marker yang dilakukan oleh pengguna, sehingga pengguna dapat melihat objek dari sisi depan, sisi kiri/kanan maupun dari sisi atas. Dengan demikian, untuk pengujian kedua agar pengguna dapat berinteraksi secara real time, dinyatakan berhasil.

Tabel 2 Pengujian Interaksi Real Time

\begin{tabular}{|c|l|c|c|l|}
\hline No & Test Factor & Objek 1 & Objek 2 & $\begin{array}{l}\text { Keterangan } \\
\text { berhasil } \\
\text { tampil }\end{array}$ \\
\hline 1 & $\begin{array}{l}\text { Menampilkan } \\
\text { objek dari sisi } \\
\text { samping }\end{array}$ & $\begin{array}{l}\text { Menampilkan } \\
\text { objek dari sisi } \\
\text { atas }\end{array}$ & &
\end{tabular}

\section{c. Pengujian Jarak Kamera Dengan Penanda atau Marker}

Pada pengujian ketiga ini, diakukan pengujian terhadap jarak antara letak kamera dengan penanda atau marker untuk mendapatkan pendeteksian penanda atau marker yang baik. Dalam penelitian yang dilakukakan oleh Kustijona dan Hakim, disimpulkan bahwa pembacaan marker oleh kamera tidak hanya dipengaruhi oleh intensitas cahaya tapi juga dipengaruhi oleh jarak antara marker dengan kamera, dimana $10 \mathrm{~cm}$ dan $100 \mathrm{~cm}$ adalah rentang minimal dan maksimal dalam menampilkan objek pada penelitian AR tersebut [10]. Sementara dari beberapa pengujian yang dilakukan dalam penelitian ini untuk mendapatkan jarak optimal antara marker dengan kamera dalam menampilkan objek, diperoleh bahwa $\pm 15 \mathrm{~cm}$ adalah jarak terdekat dan $\pm 110 \mathrm{~cm}$ adalah jarak terjauh. Hal ini dapat dilihat pada Gambar 4 berikut.
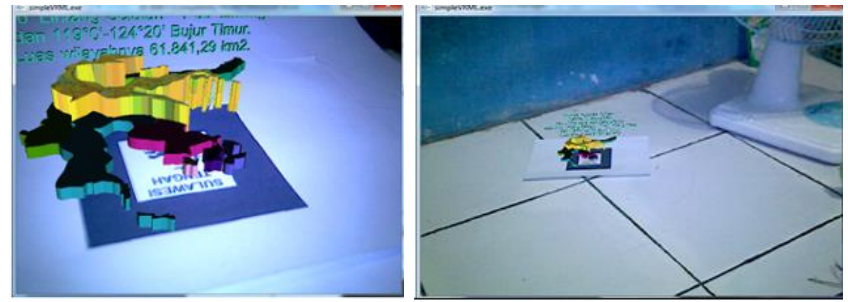

Gambar 4 Pengujian Jarak Terdekat (kiri) dan Jarak Terjauh (kanan) antara Kamera dengan Marker

Dari hasil pengujian pada Gambar 4, diperoleh bahwa objek dapat ditampilkan dengan jarak terdekat kamera $\pm 15 \mathrm{~cm}$ dan jarak terjauh $\pm 110 \mathrm{~cm}$ dari marker. Dengan demikian untuk pengujian jarak kamera dengan marker diperoleh rentang jarak optimal yaitu $15-110 \mathrm{~cm}$.

\section{d. Pengujian Menggunakan Kamera Internal dan Kamera Eksternal}

Pada pengujian terakhir, dilakukan pengujian terhadap kamera internal dan kamera eksternal dengan tujuan menguji kesiapan sistem untuk diimplementasikan pada berbagai kondisi. Gambar 5 merupakan hasil pengujian yang menunjukkan bahwa sistem yang dibuat telah siap untuk diimplementasikan baik dengan menggunakan kamera internal maupun kamera eksternal. 

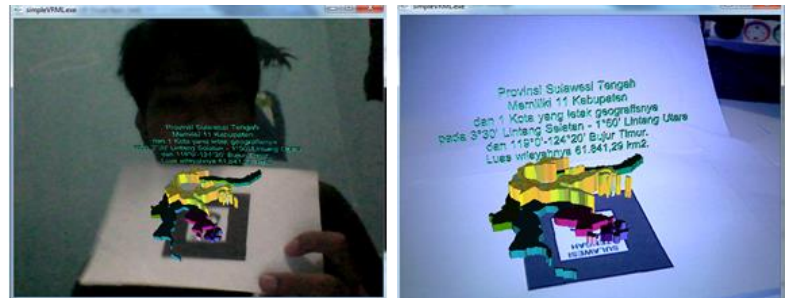

Gambar 5 Pengujian Sistem Menggunakan Kamera Internal (kiri) dan Kamera Eksternal (kanan)

Berdasarkan keempat pengujian yang dilakukan, diperoleh bahwa sistem visualisasi 3D letak geografis provinsi di Indonesia berbasis Augmented Reality telah berhasil dibuat. Hal ini dilihat dari hasil pengujian 1 dan 2, dimana sistem dapat menampilkan objek yang sesuai dengan marker dan dapat berinteraksi secara real time. Selain itu, dari pengujian 3 dan 4 dapat dilihat jika sistem juga telah siap untuk diimplementasikan dengan jarak optimal kamera-marker berkisar antara 15-110 cm dan bekerja dengan baik menggunakan kamera internal maupun eksternal. Selanjutnya, dengan adanya aplikasi visualisasi letak geografis provinsi berbasis AR ini, diharapkan para siswa dapat secara langsung mengamati objek 3 Dimensi letak geografis provinsi dan dapat berinteraksi secara real time, sehingga membuat metode pembelajaran menjadi lebih menarik.

\section{Conclusion}

Berdasarkan hasil keempat pengujian yang dilakukan, diperoleh bahwa sistem visualisasi 3D letak geografis provinsi di Indonesia berbasis Augmented Reality telah berhasil dibuat, dapat berinteraksi secara real time dan siap untuk diimplementasikan dengan jarak optimal $15-110 \mathrm{~cm}$ dan dapat menggunakan kamera internal serta kamera eksternal.

Adapun saran yang diberikan untuk penelitian selanjutnya yaitu agar dilakukan penambahan data visual untuk seluruh pulau di Indonesia dan penggunaan marker dinamis agar sistem dapat lebih fleksibel.

\section{References}

[1] A. K. Wahyudi and I. N. Pangau, "Visualisasi Perkembangan Janin Manusia menggunakan Augmented Reality dengan teknik Single Marker Multi Object," Techno.Com, vol. 17, no. 1, pp. 23-35, 2017.

[2] N. Wahyudi et al., "Augmented Reality Marker Based Tracking Visualisasi Drawing 2D ke dalam Bentuk 3D dengan Metode FAST Corner Detection,” J. Intell. Syst. Comput., vol. Vol 1 No 1, pp. 9-18, 2019.

[3] Mustika, C. G. Rampengan, R. Sanjaya, and Sofyan, "Implementasi Augmented Reality Sebagai Media Pembelajaran Interaktif," Citec J., vol. 2, no. 4, pp. 277-291, 2015.

[4] S. Aisa, "Visualisasi Metamorfosis Kupu - Kupu Berbasis Augmented Reality ( Ar ) Sebagai Media Pembelajaran Inovatif Ilmu Pengetahuan Alam," Semin. Nas. Teknol. Inf. dan Multimed. 2017, pp. 25-30, 2017.

[5] Juannita and B. P. Adhi, "Pengembangan Media Pembelajaran Sistem Pencernaan Manusia Untuk Kelas 8 SMP dengan Fitur Augmented Reality Berbasis Android (Studi Kasus : SMPN 7 Depok)," J. Pinter, vol. 1, no. 1, pp. 76-81, 2017.

[6] S. Rahma and D. Rachman, "Perancangan Aplikasi Augmented Reality Sebagai Media Pembelajaran Tata Surya Berbasis Android the Designing of Augmented Reality Application for Learning Media Android Based Solar," $J$. INSYPRO (Informastion Syst. Process., vol. 3, No 2, pp. 1-6, 2018.

[7] J. Oliver, "Teknik Marker Based Tracking Augmented Reality Untuk Visualisasi Anatomi Organ Tubuh Manusia Berbasis Android," J. Chem. Inf. Model., vol. 53, no. 9, pp. 1689-1699, 2013.

[8] C. Arum Sari, I. K. G. Darma Putra, and I. P. Arya Dharmaadi, "Penerapan Augmented Reality dalam Visualisasi Katalog Apartemen Berbasis Android," J. Ilm. Merpati (Menara Penelit. Akad. Teknol. Informasi), vol. 6, no. 2, p. $65,2018$.

[9] J. Juannita and B. Prasetya Adhi, "Pengembangan Media Pembelajaran Sistem Pencernaan Manusia Untuk Kelas 8 SMP Dengan Fitur Augmented Reality Berbasis Android (Studi Kasus : SMPN 7 Depok)," PINTER J. Pendidik. Tek. Inform. dan Komput., vol. 1, no. 1, pp. 76-81, 2017.

[10] R. Kustijono and S. R. Hakim, "Pengaruh Intensitas Cahaya Dan Jarak Pada Sistem Augmented Reality Objek Animasi," J. Penelit. Fis. dan Apl., vol. 4, no. 2, p. 8, 2014. 